\title{
Educação matemática: possibilidades de uma tendência histórico-cultural
}

\author{
Ademir Damazio* \\ Josélia Euzébio da Rosa*
}

\section{Resumo}

\begin{abstract}
A proposição, no presente texto, é a reflexão sobre as possibilidades de emergência, no contexto educacional e científico brasileiro, de uma tendência em educação matemática com fundamentos na teoria histórico-cultural. A necessidade do estudo se apresenta pela indiferença da literatura, que trata da temática, em não mencioná-la, mesmo com as evidências postas no cenário de ensino e de pesquisa. Destacam-se dois argumentos: 1) a base teórica e sua expressão nas investigações relacionadas ao ensino e à aprendizagem da matemática realizadas pelos estudiosos russos, entre os quais Vygotski, Luria, Leontiev, Davydov, Galperin, Krutestskii, Kalmykova e Talyzina; 2) grupos de pesquisa cadastrados na Plataforma Lattes do CNPq, cuja referência são os resumos ali expressos por explicitarem os respectivos objetos de estudo e os fundamentos na teoria histórico-cultural. Como decorrência, anunciam-se alguns indicativos de futuros estudos que poderiam reafirmar ou descaracterizar a tendência de educação matemática histórico-cultural.
\end{abstract}

Palavras-chave: Educação matemática. Tendências. Teoria histórico-cultural.

\section{Introdução}

Falar na possibilidade de uma tendência de educação matemática histórico-cultural, no contexto educacional e científico brasileiro, requer que expressemos, inicialmente, alguns enfrentamentos e justificativas para assim admiti-la. Para tanto, elucidamos a desconsideração, no contexto acadêmico e científico da educação matemática, para tal premência. Uma delas nos reporta à Coleção "Tendências em Educação Matemática”, da Editora Autêntica, organizada por Marcelo Borba, que não traz qualquer volume com a denominação explícita de histórico-cultural. Ou seja, não se configura entre as publicações lançadas, como: Etnomatemática,

Recebido em 15 de novembro de 2012. Aprovado em 18 de janeiro de 2013.

http://dx.doi.org/10.5335/rep.2013.3506

Professor do PGGE/UNES - Criciúma, SC. E-mail ademir@unesc.net

Professora do PPGE/UNISUL - Tubarão, SC. E-mail joselia.euzebio@yahoo.com.br 
Modelagem matemática, Didática da matemática francesa, Tecnologias e educação matemática, Educação matemática e interdisciplinaridade, História no ensino da matemática e Resolução de problemas.

Lopes e Borba (1994) indicam como tendência em educação matemática: educação matemática crítica, etnomatemática, modelagem matemática, uso de novas tecnologias e escrita e leitura no ensino da matemática.

Fiorentini (1995) vincula "os modos de conceber o ensino da matemática" às correntes pedagógicas que se apresentaram ao contexto escolar, no decorrer dos tempos, e estabelece as seguintes tendências: formalista clássica, empírico-ativista, formalista moderna, construtivismo, tecnicismo, socioetnocultural, histórico-crítica e sociointeracionista semântica. Ao discorrer sobre a última delas, o autor afirma que sua base é a teoria de Vygotski, mais especificamente em seus pressupostos referentes à linguagem.

Petronzelli (2002) admite como "tendências atuais em educação matemática": tendência epistemológica, tendência antropológica, tendência sociológica e tendência psicológica. Como as tendências nomeadas pelos autores anteriores se diluem na classificação de Petronzelli, no mínimo, esperávamos que a abordagem histórico-cultural fosse mencionada no contexto da tendência psicológica.

Para dirimir possíveis expectativas, ao nos referirmos às tendências em Educação Matemática apresentadas pela literatura, esclarecemos que a pretensão não é caracterizá-las ou discorrer sobre seus pressupostos e propostas, tanto para o contexto do ensino da Matemática, quanto para a pesquisa. O esforço foi para não adentrarmos em seus teores, uma vez que a necessidade de analisá-las - como referência ao tratamento de nossa temática - suscitou uma série de questionamentos ao status de "tendência", concedido para algumas ações pedagógicas concebidas como inovadoras para "melhorar a aprendizagem" (LOPES; BORBA, 1994, p. 50) ou "qualidade do ensino" (FIORENTINI, 1995, p. 2), em relação à matemática.

Assim, a proposição, no presente texto, é trazer evidências de argumentos para considerarmos a existência de uma tendência, com denominação similar à educação matemática histórico-cultural. Para tanto, reportamo-nos às questões relacionadas a posicionamentos do próprio campo da educação matemática, bem como aos elementos, oriundos da literatura, concebidos como caracterizadores de uma tendência no processo educacional. Para justificar a pretensão defendida, recorremos a dois argumentos. O primeiro diz respeito à base teórica, entendida como os estudos da escola russa relacionados à matemática, realizados pelos precursores e continuadores da teoria histórico-cultural. Nessa perspectiva, apresentamos os temas de pesquisa de Vygotski, Leontiev, Davydov, Galperin, Krutestskii, Kalmykova, Talyzina, entre outros. $\mathrm{O}$ segundo argumento se refere à existência 
de grupos de pesquisa cadastrados na Plataforma Lattes do Conselho Nacional de Pesquisa (CNPq). O foco foi os resumos do próprio diretório (CNPq), que traduzem os respectivos objetos de estudo e a explicitação dos fundamentos na teoria histórico-cultural.

\section{Tendência educação matemática histórico-cultural?}

De início, vale esclarecermos que a própria educação matemática, por ser uma prática social que se estabeleceu recentemente, é questionada quanto ao seu status ou não de uma disciplina, de um campo profissional, como também científico. No que diz respeito à sua disciplinarização, Miguel (2003) lembra que nenhum campo do conhecimento se constitui com base em si mesmo. Em vez disso, estabelece-se como prática social geradora de seu desenvolvimento. Entretanto, o autor questiona se o único critério para a disciplinarização da educação matemática é a existência de um corpo de pesquisadores e, por extensão, da produção de pesquisas acadêmicas sobre o suposto objeto dessa possível disciplina. De acordo com o autor (2003), tal critério é limitado, o que requer o estabelecimento de no mínimo outro, qual seja: a dimensão educativa da prática social em pauta. Como consequência, surgem uma necessidade e um interesse para tal, por parte de grupos sociais, nesse caso específico, de quem ensina e pesquisa matemática, mas, também, de algo emergente na sociedade. Miguel entende a educação matemática com teor didático-pedagógico e como objeto de pesquisa, isto é:

[...] conjunto de práticas sociais, do presente ou do passado, institucionalizadas ou não, que objetivaram, direta ou indiretamente, colocar intencionalmente em circulação a cultura matemática socialmente produzida e/ou investigar, sob qualquer aspecto e forma, esse processo de circulação (2003, p. 26).

No que se refere à educação matemática como campo profissional e de pesquisa, as discussões apresentam pontos de vista divergentes entre aqueles que têm como objeto temático de sua investigação o contexto da matemática, seu ensino e sua aprendizagem. Entre outros, vale citar Baldino (1991), que argumenta pela necessidade da diferenciação entre ensino de matemática e educação matemática. Segundo o autor, o ensino tem ligações com técnicas, e a educação vincula-se ao campo da pedagogia e da aprendizagem.

Segundo Moura, a educação matemática é um campo inserido na própria matemática, 
[...] conjunto articulado de elementos do conteúdo produzido socialmente classificados dentro de outro conjunto chamado de Matemática. Este conhecimento deve ser perpetuado, difundido e desenvolvido como condição da permanência e avanço da cultura humana. A Educação Matemática deixa de ser definida apenas como ensino de Matemática quando faz parte de um projeto pedagógico, que tratará o conteúdo de matemática como conhecimento que responde a determinadas questões que inquietaram e inquietam o homem ao ter que resolver os seus problemas sociais - aqui se incluem aqueles de ordem filosófica, psicológica, sociológica e cultural. A Educação é matemática quando tem no ensino a presença das questões próprias da educação com o conteúdo da matemática, ou seja: o porquê ensinar matemática, o para quê ensiná-la, o como fazê-lo e para quem deve ser feito. A articulação destes elementos é que atribui ao ensino a nova qualidade que o transforma em projeto educativo (1992, p. 12-13).

D’Ambrósio (1996) concebe a educação matemática em seu aspecto político e sociocultural. Seu pressuposto é de que o entendimento da realidade se reverte em instrumento dos alunos para a possibilidade de construção de uma sociedade mais justa para todos. Giardinetto (2002) considera o termo "educação matemática" como óbvio, uma vez que educação denota um processo amplo que inclui tanto a educação formal quanto a informal. Por isso, admite o termo "ensino de matemática" como o mais apropriado, por expressar as diversas contribuições ao ato pedagógico de socialização do saber matemático escolar.

Conforme Floriani (2000), a educação matemática tem como tarefa a condução dos estudos no processo de construção do conhecimento matemático, concebendo a matemática como advinda da prática social, isto é, da atividade econômica, política e social de determinada época. Skovsmose entende que a "educação matemática envolve ideias e significados diferentes e até mesmo incoerentes" (2001, p. 20), no que se refere aos princípios filosóficos e pedagógicos de ensino. Relacionados a esses princípios, distingue três alternativas em educação matemática - estruturalismo, pragmatismo e orientação ao processo - e mostra as contradições existentes entre eles.

Fiorentini e Lorenzato consideram a educação matemática como componente da área das ciências sociais ou humanas e se voltam ao estudo do ensino e da aprendizagem da matemática. Porém, a condição para ensinar e aprender esse componente curricular é o domínio simultâneo do conteúdo matemático, das ideias e dos processos pedagógicos vinculados "à transmissão/assimilação e/ou à apropriação/construção do saber matemático escolar" (2006, p. 5). Desse modo, a educação matemática transita, interdisciplinarmente, entre outras, pela matemática, psicologia, sociologia, pedagogia, epistemologia, pelas ciências cognitivas e pela semiótica.

Em vez de educação matemática, Vilela avalia ser mais adequada a denominação "conhecimentos sobre o ensino e a aprendizagem de matemática" (2008, 
p. 43-44, grifo da autora), quando a referência é os estudos reveladores dos processos em foco, desde que levem em consideração a formação humana e o desenvolvimento da matemática como ciência.

Portanto, consequência da sua recente história, o que, basicamente, se considera educação matemática e sua expressão em "tendências" ainda convive com interrogações sobre sua identidade, seus domínios, suas fronteiras, suas investigações e a própria denominação. Com a consciência do não esgotamento desse debate, voltemos à pergunta: "tendência educação matemática histórico-cultural?". Reafirmamos que a questão só tem validade se entendida no contexto da sua não inclusão entre o rol daquelas que a literatura considera como "tendência".

Porém, vem à tona a necessidade de critérios definidores para se considerar uma determinada proposição educativa como tendência. Nesse sentido, recorremos a Ferreira:

Entende-se por tendência toda e qualquer orientação de cunho filosófico e pedagógico que determina padrões e ações educativas, ainda que esteja desprovida de uma reflexão e de uma intencionalidade mais concreta. Uma tendência pedagógica é, na verdade, uma inclinação por pensamentos e comportamentos pedagógicos lidos na história da educação ou mesmo em outras práticas pedagógicas hodiernas. Muitas vezes, em uma escola, em uma comunidade, percebem-se práticas educativas cuja orientação embora existente não é fruto de uma reflexão mais apurada, consensada. Assim, vão-se reproduzindo e tornam-se explicações do processo educativo, enraizando-se na dinâmica escolar. Por seu caráter provisório, já que demandam uma maior reflexão, estas orientações são consideradas tendências. Se fruto de análise, de pesquisas, de estudo passam desta configuração ao status de uma teoria, de uma proposta educativa (2003, p. 14, grifo nosso).

Em síntese, para a autora em referência, a constituição de uma tendência é galgada em bases filosóficas e pedagógicas, caracterizada por ações educativas que se tornam consenso, ao se expandirem nos contextos escolares. Lopes e Borba consideram como "verdadeiras tendências" as formas de trabalhos com base em diferentes teorias e posições epistemológicas que são "usadas por muitos professores, ou estão servindo como recursos adotados esporadicamente, mas com resultados alentadores" (1994, p. 50).

As duas definições têm algo em comum: uma tendência apresenta um fundamento teórico. Nesse sentido é que consideramos dois princípios essenciais para um pesquisador e, também, para os professores de qualquer nível de ensino. $\mathrm{O}$ primeiro concerne à explicitação da matriz teórica, pois se torna difícil admitir que um pesquisador não tenha conhecimento das bases epistemológicas, filosóficas e pedagógicas que fundamentam seus estudos. Aquiescemos com Triviños (1987), ao chamar atenção sobre a necessidade de disciplina teórica no processo investigativo e docente, isto é, de se evitar a junção de várias teorias que, muitas vezes, têm pressupostos antagônicos. O segundo é de que elas devem apontar as implicações 
de suas múltiplas determinações no processo educativo matemático escolar. Por exemplo, explicitar em seu projeto político-pedagógico ou nas suas investigações as concepções de matemática, ensino, relação professor/aluno, entre tantas.

Entendemos que a elucidação desses princípios, por uma tendência, contribuirá para que as manifestações no processo educacional e investigativo ocorram sem ecletismo ou, no mínimo, com um ecletismo consciente. Dito de outro modo, o professor e o pesquisador que a adotarem o farão de forma tal que explicite a distinção entre suas pertinências e incoerências. Contudo, vale expressar a preocupação quando a preferência é pela opção eclética, pois a construção de respostas para perguntas essenciais referentes a concepções trilharia pelos caminhos das contradições. Por exemplo: seria possível unir posicionamentos tão divergentes como o a priorismo e o a posteriorismo da natureza do conhecimento matemático? $\mathrm{Ou}$, então, em questões psicológicas: quem antecede ou precede, aprendizagem ou desenvolvimento?

Diante desse cenário, poderíamos até desistir da discussão sobre o status de uma tendência educação matemática histórico-cultural. Porém, continuamos com a posição assumida de que a teoria histórico-cultural tem sido adotada como fundamentos de estudos produzidos no cenário científico brasileiro e mundial, voltados para a matemática no contexto educativo. Isso significa que ela traz contribuições para o estudo sobre os mesmos objetos e temáticas que aquelas apontadas pela literatura, a seguir mencionadas.

Em estudo anterior, Damazio (2008) - com orientação nas leituras, respectivamente, da Coleção publicada pela Editora Autêntica e Fiorentini (1995), entre outras - distingue dois grupos de tendência em educação matemática. $\mathrm{O}$ primeiro se refere às tendências que emergiram no campo do ensino específico da matemática, quais sejam: modelagem matemática, didática da matemática francesa, tecnologias e educação matemática, educação matemática e interdisciplinaridade, história e ensino da matemática, resolução de problemas e etnomatemática. Compõem o segundo grupo as tendências que se apresentaram a partir das bases teóricas da pedagogia: formalista clássica, formalista moderna, empírico-ativista, tecnicista, construtivista, socioetnoculturalista, sociointeracionista semântica, histórico-crítica. Ao expressarmos a possibilidade de uma tendência de pesquisa e ensino de educação matemática histórico-cultural, a colocamos entre aquelas que compõem o segundo grupo. Para tanto, adotamos dois argumentos: sua base teórica e grupos de pesquisa. 


\section{A base teórica}

Os fundamentos da tendência em foco consistem na teoria histórico-cultural e na teoria da atividade, a qual, como mencionado anteriormente, tem sua matriz no materialismo histórico e dialético. Sendo assim, estabelece diálogos com a filosofia, a epistemologia, a psicologia, a sociologia, a pedagogia e, como trataremos adiante, com o ensino e a aprendizagem da matemática.

A teoria histórico-cultural busca explicar a vida social pelas mudanças qualitativas das formas especificamente humanas. Para tanto, recorre à gênese das mediações que propiciaram o surgimento de novos modos de existência e possibilidades do seu devir. A vida cotidiana, o conhecimento até então apropriado, as práticas sociais e as funções psicológicas elementares são as referências, o ponto de partida para a investigação histórica com a pretensão de compreender o passado dos indivíduos e a sociedade nas quais se inserem. Vygotski (1993) assume o posicionamento de Engels de que o trabalho, bem como a fabricação e o uso dos instrumentos promovem a mediação da relação entre o homem e a natureza geradora de transformações mútuas. Esses mediadores se constituem em condições necessárias para o surgimento das funções psicológicas superiores e do desenvolvimento histórico dos seres humanos. Segundo Vygotski (1993), no atual estágio de desenvolvimento da humanidade, é inegável o papel da apropriação do conhecimento científico para o desenvolvimento do homem e das suas funções psicológicas superiores. Nesse sentido, considera a aprendizagem como uma necessidade universal para que os indivíduos desenvolvam as características humanas não naturais, formadas historicamente.

Desse modo, o enfoque histórico-cultural, apresentado por Vygotski desde a segunda década do século XX, traz um novo objeto para a psicologia: a atividade humana, definida como mediadora da relação entre o homem e a realidade a transformar. Os pressupostos vygotskianos foram estudados por seus colaboradores e continuadores contemporâneos.

Luria (1978) adotou o pressuposto de que experiências sociais diferentes proporcionam um conhecimento distinto e estimulam diversos tipos de processos mentais. Contudo, para tal, conforme Leontiev (1978), a condição essencial é atividade laboral do homem. Esse autor desenvolveu a teoria da atividade com base no paradigma da produção material, interpretação marxista do desenvolvimento humano, e resgata, em especial, o papel do trabalho na formação da consciência. Toda atividade humana, segundo Leontiev (1978), tem como qualidade especial e peculiar o fato de ser sempre "social". Ela surge sob determinadas condições, que resultam das relações que os homens estabelecem entre si ao longo da história. 
A sua característica ímpar de "ser social" explica a estrutura comum tanto da atividade externa do homem como da sua atividade interna, as quais são determinadas por motivos que levam o indivíduo a se colocar em atividade e por fins a serem alcançados. Requerem a integração de determinadas ações que são executadas por operações. Entretanto, essa estrutura da atividade recebe de Davydov (1999) outros elementos conceituais, quais sejam: desejos, necessidades, emoções, ações, motivos para as ações, meios usados para as ações, planos (perceptual, mnemônico, pensamento criativo), que se referem tanto à cognição quanto à vontade.

Pela atividade, os indivíduos estabelecem relações sociais com a realidade, com os outros indivíduos e consigo mesmos. Conforme Leontiev (1978), a atividade de cada indivíduo depende: do lugar que ocupa na sociedade, das condições e das apropriações que lhes dão as características particulares. As fases do desenvolvimento humano são caracterizadas em três atividades principais: o jogo, que marca a infância pré-escolar; o estudo, no período escolar; e o trabalho, na idade adulta.

Porém, Elkonin (1987) continua os estudos de Leontiev e estabelece como os principais estágios de desenvolvimento por que os sujeitos passam: comunicação emocional do bebê, atividade objetal manipulatória, jogo de papéis, atividade de estudo, comunicação íntima pessoal e atividade profissional.

Davydov (1999) anuncia os tipos de atividades desenvolvidas no curso da história do ser humano. O trabalho é visto como o gênero fundamental da atividade, seguido de atividade artística, que antecede a atividade no campo da moral, da lei, da religião. Também, adota outro princípio básico para estabelecer as atividades que surgem no processo ontogenético ou reprodutivas: manipulatória do objeto, de brincadeira e estudo.

Galperin (1986) estudou, detalhadamente, as etapas da transformação da atividade externa em interna. Elaborou a teoria da assimilação por etapas para o processo de apropriação de conceitos científicos, que obedece as seguintes etapas: motivacional, formação da base orientadora da ação, formação da ação no plano material ou materializada, formação da ação na linguagem externa, conversação para si, ação no plano mental.

Dedicaram-se à investigação sobre o processo de apropriação dos conceitos científicos Galperin (1986) e Davydov (1999). Para tanto, este último traz à tona a tese da escola científica de Vygotski de que:

[...] o ensino e a educação constituem as formas universais do desenvolvimento psíquico das crianças; nelas se expressa a colaboração entre os adultos e as crianças, orientada de modo que elas se apropriem das riquezas da cultura material e espiritual, elaboradas pela humanidade. O ensino e a educação são os meios com que os adultos organizam a atividade das crianças, graças a tal realização elas reproduzem em si as necessidades surgidas historicamente, indispensáveis para a solução exitosa das diversas tarefas da vida produtiva e cívica das pessoas (1988, p. 243). 
Contudo, Davydov (1988) avalia como insuficiente o simples fato de o estudante ter acesso à escola e nela permanecer por um determinado tempo de sua vida. O essencial é que ele esteja e se sinta em atividade de estudo. Para tanto, o método a se adotar no ensino deve primar pela solução de tarefas cognitivas - que coloquem o estudante em ação investigativa - que lhe assegurem a transmissão da experiência criadora.

Assim, nessa perspectiva teórica, a atividade de pesquisa em educação matemática tem como foco o contexto em que ocorre a apropriação das relações matemáticas presentes no coletivo. Por sinal, há preocupações de investigações que se manifestam entre os pesquisadores russos da teoria histórico-cultural. Vygotski (1993) mesmo, ao estudar o desenvolvimento dos conceitos científicos na infância e na idade de transição, apresenta pressupostos da formação do pensamento aritmético e algébrico. Em seu texto (1995), há um capítulo que trata, especificamente, do desenvolvimento das operações aritméticas, em que questiona se as percepções diretas das quantidades e das operações com esses valores, presentes na aritmética pré-escolar, conduzem ao desenvolvimento do pensamento teórico aritmético. Ao deixar dúvidas de qual seria o melhor tratamento pedagógico para o desenvolvimento das operações, informa que ocorrem três níveis de desenvolvimento do pensamento aritmético: natural, mediado e cultural. Acrescenta que a passagem de um nível para outro é sempre conflitiva. Contudo, afirma que a característica fundamental de desenvolvimento das funções psicológicas superiores é pensamento algébrico:

La asimilación del álgebra eleva a un nivel superior el pensamiento aritmético, permitiendo comprender cualquier operación aritmética como un caso particular de una algebraica, proporcionando una visión más libre, más abstracta y más generalizada y con ello más mas profunda y rica a las operaciones con cantidades concretas. Exactamente igual que el álgebra libera el pensamiento del niño del cautiverio de las dependencias numéricas concretas y lo eleva al nivel de un pensamiento más generalizado (VYGOTSKI, 1993, p. 198).

Kruteskii (1991) pesquisou o desenvolvimento do pensamento dos alunos considerados com pouca capacidade para a matemática, com foco para a presença dos dois componentes da atividade intelectual: o visual-imaginativo e o lógico-verbal. Concluiu que, para um melhor desempenho dos alunos na realização das tarefas de estudos relacionadas a conceitos matemáticos, deve haver o predomínio do componente lógico-verbal sobre o visual-imaginativo. Em suas palavras: "Embora o componente lógico-verbal não determine infalivelmente a capacidade matemática, no entanto representa uma condição necessária" (KRUTESKII, 1991, p. 84).

Tais conclusões têm respaldo em Luria (1978), que, ao pesquisar a correlação entre os componentes ativo-visuais e os lógico-verbais no emprego dos silogismos e 
experimentos relacionados com a definição dos conceitos, assim conclui: “A princípio, o pensamento opera com formas 'ampliadas', utiliza as operações ativo-visuais que haviam dominado até o momento. Aos poucos, o indivíduo supera os limites anteriores e se familiariza com as formas mais desenvolvidas de abstrações e generalizações" (LURIA, 1978, p. 116). Ou seja, na apropriação dos conceitos científicos promovida pelo ensino, os indivíduos trocam o componente visual-imaginativo pelo componente lógico-verbal, porém, sem desprezar aquele de vez.

Kalmykova (1991) estudou a aprendizagem de resolução de problemas matemáticos por parte de alunos cujos professores eram considerados bons, uma vez que sua atividade pedagógica era caracterizada pela proposição de tarefas ricas de elementos analítico-sintéticos. A autora admite que as operações aritméticas e a solução de problemas têm uma base comum, por se tratarem de formas de pensamento que requerem processos de análise e síntese, com diversos graus de dificuldades. Salienta, contudo, que ambas apresentam diferenças significativas quanto à sua amplitude, pois solucionar um problema requer muito mais atividade analítico-sintética do que resolver uma operação aritmética.

De acordo com Kalmykova (1991), as palavras são "estímulos multiformes", quando inseridas no âmbito da concomitância da aprendizagem de conceitos matemáticos como de resolução de problemas, dado que uma delas pode estar ligada a uma diferente ação mental, em distintas situações. A análise e a síntese ocorrem dialeticamente interligadas, na medida em que uma síntese cria uma nova realidade e a submete a uma nova análise, o que estabelece novas relações entre fatos anteriores e aqueles em processo de síntese. Uma boa formação de conceitos matemáticos, segundo Kalmykova (1991), requer o uso adequado de uma diversidade de materiais didáticos, desde que se evite abusiva experiência sensorial.

Galperin formulou a teoria do processo de formação e apropriação de conceitos por etapas para a investigação relacionada à aprendizagem da matemática. Nesse sentido, Galperin e Talyzina (1967) pesquisaram o processo de apropriação, pelos estudantes de $5^{\underline{a}}, 6^{\underline{a}}$ e $7^{\underline{a}}$ séries do ensino fundamental, de alguns conceitos geométricos elementares. Concluíram os autores que os estudantes dominam completamente os conceitos geométricos quando seguem, rigorosamente, todas as etapas. Para tal, respaldam-se em dados que explicitavam a atribuição de respostas corretas aos problemas propostos e a elaboração de definições precisas. Qualquer omissão - por exemplo, as primeiras etapas, que não exigem a verbalização - impossibilita o desenvolvimento do conceito.

A transmissão gradual da matéria completamente detalhada (forma "materializada" do processo de pensamento) ao "puramente verbal" e depois a etapa de "pensar em silêncio" têm o efeito de que o conteúdo e a lógica do processo de pensamento, em todas as formas, se fazem compreensíveis e acessíveis às crianças (GALPERIN; TALYZINA, 1967, p. 300). 
Os autores enfatizam que o emprego desse método tem efeito positivo com alunos, até então desinteressados nas aulas de matemática, pois passam a ter um envolvimento ativo nas tarefas propostas.

Mais recentemente, Talyzina dedicou-se ao estudo das implicações da teoria da atividade no processo pedagógico. Suas investigações se dirigiram para questões específicas do processo de apropriação dos conceitos matemáticos, em situação de ensino e aprendizagem. Nesse sentido, vale mencionarmos a organização do livro La formación de las habilidades del pensamiento matemático (TALYZINA, 2001), que aborda os seguintes temas: formação dos conceitos matemáticos (Talyzina); o ensino da matemática na escola primária (Salmina); formação da habilidades gerais para a solução de problemas aritméticos (Nikola e Talyzina); formação das habilidades que se encontram na base da demonstração geométrica (Butkin); formação das habilidades generalizadas do pensamento geométrico (Volodarskaya); e formação do método geral para a solução de problemas com construções geométricas (Volodarskaya e Nikitiuk).

Davydov tem sido considerado o mentor de uma proposição pedagógica mais arrojada e atual da abordagem histórico-cultural. Sua defesa é no sentido de que o objetivo do ensino escolar deveria ser o desenvolvimento do pensamento teórico, em detrimento do pensamento empírico. O autor (1998, p. 197) não desconsidera o valor do pensamento empírico na vida cotidiana, mas adverte que ele "obstaculiza o caminho", ao se pretender que os estudantes entendam o conhecimento teórico.

A atividade de estudo, por meio de suas tarefas particulares, deve orientar o aluno para a apropriação das relações mais gerais que caracterizam um determinado conceito matemático e, gradativamente, conduzam para as relações concretas. Com tal apropriação, a relação se transforma em simbólico e se converte em abstração com conteúdo (DAVYDOV, 1982).

Davydov (1982) traduz esses princípios para o processo de ensino-aprendizagem da matemática, mais especificamente para o conceito de número. Afirma que, desde a primeira série escolar, o aluno deve adquirir uma concepção circunstanciada e válida de número real, considerado o conhecimento teórico e relacionado ao conceito de grandeza. Em sua proposta, na primeira etapa, o aluno estabelece comparação entre grandezas (comprimento, superfície, peso, volume e outros) e uso de materiais (tiras de papel, palitos, blocos). As noções adquiridas são representadas, não por signos numéricos $(1,2,3,4,5,6,7,8,9,0)$, mas, inicialmente, por linhas desenhadas em um papel e, posteriormente, por letras e por símbolos, com anotações do tipo $a=b, a>b$ e $a<b$, consideradas as primeiras abstrações.

A segunda etapa se caracteriza pela apresentação de problemas em que dois objetos $a$ e $b$ não podem ser comparados diretamente, sendo necessária uma medi- 
da $c$ que se inclua $n$ vezes nas duas grandezas estabelecidas. Consequentemente, o aluno aprende as relações multiplicativas $a / c$ e $b / c$ e faz as seguintes anotações: num primeiro momento, por traços; depois, com os signos numéricos; por último, na forma algébrica do tipo $a / c=5$. Para Davydov (1982, p. 436), a proposta estreita consideravelmente o divórcio entre a álgebra e a aritmética, o que permite aos alunos a resolução de equações e a identificação das propriedades dos números desde a primeira série, sem o "concretismo" defendido nos meios educacionais.

A proposta de Davydov (1982) contrapõe-se radicalmente aos modelos pedagógicos predominantes nos sistemas de ensino que denomina de tradicionais, pela não consideração das capacidades atingidas pelo homem da atualidade. E, como tal, constitui-se na autêntica objetivação dos pressupostos materialista dialético e histórico, bem como da teoria histórico-cultural no ensino da matemática. Traduz-se num modo de organização do ensino sem precedente, por várias razões. Uma delas, por colocar os estudantes em atividade de estudo em níveis do que de mais atual a humanidade produziu. Também, por estabelecer com objetivo a formação do pensamento teórico, proporcionado pela apropriação dos conceitos científicos, a partir do seu modo geral (essência), em vez de priorizar o pensamento empírico, com ênfase no estudo dos conceitos cotidianos e de situações particulares. Além disso, por permitir o trânsito concomitante pela álgebra, geometria e aritmética, o que se soma ao fato de estabelecer que, desde o primeiro ano, os estudantes se envolvem num sistema de tarefas particulares de estudo em que a ideia central - geral - do conceito é focada. Ainda, por focar, desde o primeiro ano escolar, o conceito de número real, em vez de natural. Por fim, por contemplar a oportunidade para que todos os estudantes da escola pública se apropriem de conceitos.

Essas resenhas, mesmo que sucintas, expressam o interesse dos pesquisadores russos pelo papel peculiar do desenvolvimento do pensamento matemático na formação das funções psicológicas superiores. Se entendidas, essa produção teórica se constitui em aliada ao desafio da busca de conhecimento da realidade social e seu poder na constituição dos indivíduos. Para tanto, o conhecimento matemático é tomado como produção humana ocorrida historicamente no desenvolvimento social da própria humanidade. Portanto, "deixa de ser uma qualidade interna do espírito humano, como advogam os idealistas, bem como uma relação de causa e efeito, como afirmam as teorias mecanicistas" (DAMAZIO, 2000, p. 45).

A formação de um conceito matemático, em situação de ensino e aprendizagem escolar, atende o princípio da relação interno/externo como algo social. De acordo Vygotski, "toda a função desse desenvolvimento aparece em cena duas vezes, em dois planos; primeiro no plano social e depois no plano psicológico, a princípio entre os homens como categoria interpsíquica e logo depois no interior do ser humano como categoria intrapsíquica" (1995, p. 150). 
Desse modo, a atividade pedagógica e a de pesquisa em educação matemática procuram focar tanto o modo de organização do ensino quanto as relações matemáticas produzidas historicamente - conceitos de domínio social -, bem como as formas de suas apropriações pelos estudantes. Isso requer que olhemos para a matemática como uma produção dos homens nas suas relações sociais, que sofrem determinações de diversas ordens e, por isso, passível de certezas e incertezas.

\section{Os grupos de pesquisa}

O segundo argumento que justifica nosso posicionamento da tendência educação matemática histórico-cultural é a presença de grupos de pesquisa em universidades brasileiras, procedendo, para tanto, desde 1992, ao levantamento no diretório dos grupos de pesquisa da Plataforma Lattes do CNPq. Apresentamos o quadro dos grupos em ordem cronológica de cadastro e, na sequência, a descrição de seus respectivos ementários.

\begin{tabular}{|c|c|c|c|c|}
\hline & Instituição & Nome do grupo & $\begin{array}{l}\text { Ano de } \\
\text { formação }\end{array}$ & Líder(es) do grupo \\
\hline 1 & $\begin{array}{r}\text { Universidade Estadual de } \\
\text { Campinas - UNICAMP }\end{array}$ & $\begin{array}{c}\text { Prática Pedagógica em } \\
\text { Matemática }\end{array}$ & 1995 & $\begin{array}{l}\text { Dione Lucchesi de } \\
\text { Carvalho e Dario Fiorentini }\end{array}$ \\
\hline 2 & $\begin{array}{l}\text { Universidade de } \\
\text { Passo Fundo - UPF }\end{array}$ & $\begin{array}{l}\text { Teoria histórico-cultural e } \\
\text { educação matemática }\end{array}$ & 1997 & Neiva Ignês Grando \\
\hline 3 & $\begin{array}{l}\text { Universidade do Extremo Sul } \\
\text { Catarinense - UNESC }\end{array}$ & $\begin{array}{l}\text { Educação matemática: uma } \\
\text { abordagem histórico-cultural }\end{array}$ & 2001 & Ademir Damazio \\
\hline 4 & $\begin{array}{l}\text { Universidade de } \\
\text { São Paulo - USP }\end{array}$ & $\begin{array}{r}\text { Grupo de Estudos e Pesquisa } \\
\text { sobre Atividade Pedagógica }\end{array}$ & 2002 & $\begin{array}{c}\text { Manoel Oriosvaldo de Moura } \\
\text { e Elaine Sampaio Araujo }\end{array}$ \\
\hline 5 & $\begin{array}{c}\text { Universidade Bandeirante de } \\
\text { São Paulo - UNIBAN }\end{array}$ & $\begin{array}{c}\text { Processos de } \\
\text { ensino - aprendizagem em } \\
\text { educação matemática }\end{array}$ & 2004 & $\begin{array}{c}\text { Maria Helena Palma de } \\
\text { Oliveira }\end{array}$ \\
\hline 6 & $\begin{array}{c}\text { Universidade Estadual } \\
\text { Paulista Júlio de Mesquita } \\
\text { Filho - UNESP }\end{array}$ & $\begin{array}{c}\text { A pedagogia histórico-crítica e o } \\
\text { ensino-aprendizagem da } \\
\text { matemática }\end{array}$ & 2004 & Mara Sueli Simão Moraes \\
\hline 7 & $\begin{array}{l}\text { Universidade Federal de } \\
\text { Minas Gerais - UFMG }\end{array}$ & $\begin{array}{c}\text { Grupo de pesquisa e estudos } \\
\text { histórico-culturais em } \\
\text { educação matemática e em } \\
\text { ciências }\end{array}$ & 2008 & $\begin{array}{c}\text { Jussara de Loila Araújo } \\
\text { Maria Manoela Martins } \\
\text { Soares David }\end{array}$ \\
\hline
\end{tabular}

Fonte: Formulado pelo autor com base na Plataforma Lattes do CNPq. Disponível em: <http://www.cnpq.br/gpesq/ apresentacao.htm>. Acesso em: 27 mar. 2010.

Quadro 1 - Grupos de pesquisa em educação matemática na abordagem histórico-cultural

1) O grupo Prática pedagógica em matemática tem como objeto de estudo a atividade pedagógica e docente em matemática (saberes, práticas e inovações, produzidos sob uma epistemologia de prática reflexiva e investigativa) e os processos de formação e desenvolvimento docente. Atualmente, o objeto de estudo do grupo 
consiste nas práticas de ensinar e aprender matemática na escola básica e na universidade sob uma perspectiva do desenvolvimento do letramento como prática social sob um enfoque histórico-cultural. A modalidade de pesquisa do grupo é, predominantemente, qualitativa e interpretativa sob uma abordagem etnográfica. Tem havido, também, investigações sob a modalidade de estado da arte e de meta-análises de pesquisas, cujo objeto de estudo é as práticas de ensinar e aprender matemática e práticas de formação/constituição profissional do professor (PRAPM, 2010).

2) O grupo Teoria histórico-cultural e educação matemática tem voltado sua atenção para a complexidade escolar, especialmente para a sala de aula, o currículo e os processos pedagógicos dessa disciplina. Os seus integrantes são pesquisadores da Universidade de Passo Fundo, estudantes e egressos do Programa de Pós-Graduação em Educação da instituição. O conhecimento gerado pelas pesquisas realizadas no grupo vem sendo divulgado em eventos científicos, regionais, nacionais e internacionais e em periódicos da área de educação, em especial, de educação matemática, que se somam à publicação de livros e capítulos de livros (TEORIA..., 2010).

3) O grupo Educação matemática: uma abordagem histórico-cultural tem suas raízes no início dos anos 1990 e se consolidou no ano 2000. A preocupação básica do grupo é o estudo do processo de formação/apropriação/socialização de conceitos matemáticos em contextos intra e extraescolar. A base teórica corresponde à abordagem histórico-cultural elaborada por Vygotski e seus continuadores. Recentemente, além das pesquisas individuais com base nesse referencial, o olhar do coletivo do grupo está voltado para a proposta do ensino de matemática de Davydov. Além das obras em espanhol e inglês, o grupo de pesquisadores analisa os livros didáticos elaborados por Davydov e seus colaboradores no idioma russo (EDUCAÇÃO..., 2010).

4) O Grupo de estudos e pesquisa sobre atividade pedagógica realiza pesquisas segundo os princípios teórico-metodológicos da abordagem histórico-cultural, focalizando os elementos constitutivos dos processos de ensino e de aprendizagem na formação inicial e contínua de professores e pesquisadores, exercitando a indissociabilidade entre ensino, pesquisa e extensão. Há mais de uma década, professores da rede de ensino, conjuntamente com alunos dos cursos de graduação e de pós-graduação, têm exercitado a reflexão sobre atividade de ensino, pressupondo a atividade de aprendizagem e focalizando a história do conceito em matemática. Como produto dessas atividades, destacam-se: elaboração, execução e avaliação de oficinas pedagógicas, centradas em atividades orientadoras de ensino; acompanhamento pedagógico de profissionais da rede pública de ensino em diversas ad- 
ministrações públicas; estudo bibliográfico dos pressupostos teórico-metodológicos da organização do ensino; a produção e a socialização de conhecimento acadêmico específico nesse campo. As ações dos sujeitos, profissionais que atuam na educação infantil em todos os níveis de ensino, abrangem os processos de formação inicial e continuada de professores, tanto nos limites da Faculdade de Educação e Colégio de Aplicação como nos diferentes âmbitos da administração pública (GRUPO..., 2010).

5) O grupo Processos de ensino-aprendizagem em educação matemática tem como objetivo discutir, refletir e aprofundar o conhecimento sobre os processos de ensino-aprendizagem em educação matemática sob uma abordagem histórico-cultural, com ênfase na perspectiva de Lev S. Vygotski. Nesse sentido, vem realizando pesquisas voltadas para o entendimento dos processos metacognitivos, mais especificamente os de autorregulação da aprendizagem. Realiza estudo sobre a atenção e a interação na autorregulação da aprendizagem de estatística de alunos universitários de cursos tecnológicos da grande São Paulo (PROCESSOS..., 2010).

6) O grupo de pesquisa A pedagogia histórico-crítica e o ensino-aprendizagem da matemática, vinculado ao Programa de Pós-Graduação em Educação para a Ciência, área de concentração em Ensino de Ciências, pretende promover um espaço de reflexão sobre a importância da defesa da apropriação do saber escolar para a formação dos indivíduos e as implicações daí decorrentes para a viabilização de um ensino e aprendizagem de matemática que instrumentalize os indivíduos numa perspectiva crítica perante a realidade social. O referencial teórico desses estudos é a denominada "pedagogia histórico-crítica", tendência pedagógica de fundamentação marxista, inicialmente elaborada por Dermeval Saviani (A PEDAGOGIA..., 2010).

7) O Grupo de pesquisa e estudos histórico-culturais em educação matemática e em ciências dedica-se à pesquisa nos campos da educação matemática, da educação em ciências e áreas de conhecimento correlatas. Fundamenta seus trabalhos em uma perspectiva teórica baseada na abordagem histórico-cultural, a qual tem origem na escola soviética de psicologia, fundada por Vygotsky, Leontev e Lúria, no início do século XX, e em perspectivas sociológicas, como a de Marx. Ampara-se, em especial, na teoria da atividade, que considera a atividade como unidade básica do desenvolvimento humano e a atividade humana como um fenômeno mediado histórica e culturalmente (GRUPO DE..., 2010).

Um estudo das produções desses sete grupos traria questões que interessariam como argumentos ainda maiores para considerar a teoria histórico-cultural como base de tendência em educação matemática. Para tanto, poder-se-ia focá-lo, no mínimo, em duas abrangências. Uma delas estaria isenta de maiores preocupa- 
ções com a edificação da educação matemática, pois adotaria os mesmos critérios de status científicos para as pesquisas desenvolvidas com base naquelas tendências admitidas pela comunidade de educadores matemáticos. Uma segunda abrangência seria considerá-la em sua própria matriz teórica, isto é, uma prática social singular, que entende a apropriação do conhecimento matemático, em seu mais complexo nível de elaboração, como necessária à formação do homem atual. Para tanto, seria necessário um processo de análise das múltiplas determinações que geraram o conhecimento matemático, bem como os modos de organização do ensino para sua transmissão/apropriação. Além disso, essas investigações traduziriam o real compromisso e o entendimento dos grupos sobre a própria base teórica.

O suposto é que a opção pelos membros desses grupos por essa teoria ocorreu por vontade de fazer escolhas conscientes, ao operarem com o significado de suas ações docentes e de pesquisa (VYGOTSKI, 1993). E, para atender os próprios pressupostos de base histórico-cultural, o significado das pesquisas que lhe desenvolveram uma vontade foi a aprendizagem da matemática, por parte dos estudantes, como um instrumento de formação humana para que compreendam a produção da realidade social e as possibilidades de transformá-las.

\section{Considerações finais}

Assumimos o posicionamento de que a teoria histórico-cultural se constitui em fundamentos para estudos produzidos no cenário científico brasileiro e mundial voltados para a matemática no contexto educacional. Sendo ou não uma tendência, ela tem contribuído para a reflexão sobre os mesmos objetos e temáticas que abordam aquelas apontadas na coleção anteriormente citada, cujos critérios para assumi-las com tal status carecem de novo entendimento. A base teórica e as evidências de grupos de pesquisa são argumentos que justificam a existência de investigações e de propostas pedagógicas fundamentadas na teoria histórico-cultural. Eis as perguntas que surgem: são eles os critérios necessários e suficientes para determinar a existência de uma tendência em educação matemática? Que outros critérios podem existir e por que são estabelecidos? Faz-se importante estabelecer critérios? Internacionalmente, há contribuição dessa teoria para a educação matemática?

Contudo, não é possível negar a existência, nos meios acadêmicos, de pesquisadores que adotam o referencial em foco para fundamentar estudos científicos sobre a matemática no contexto escolar. Vale reafirmar a necessidade de estudo mais exaustivo - com outros critérios/argumentos e fontes - que aponte o estado da arte das produções científicas com essa abordagem teórica e que destaque suas características, seus equívocos, bem como contribuições para a educação matemática brasileira. 
A abrangência desses estudos aumenta se considerarmos que os grupos mencionados vinculam-se a Programas de Pós-Graduação em Educação. Isso revela as possibilidades de participação de pesquisadores dos cursos de graduação (iniciação científica), de outros Programas de Pós-Graduação, como também de professores de todos os níveis de ensino. Como consequência, a produção científica se expande pelas dissertações e teses produzidas, pela publicação de artigos em periódicos, livros ou coletâneas, bem como pela participação em eventos científicos.

Enfim, o referencial histórico-cultural tem se solidificado em grupos de pesquisa, que, pela descrição de seus ementários, focam o entendimento da realidade do processo educativo matemático em seus aspectos epistemológicos e didáticos. Além dos questionamentos levantados anteriormente, salientam-se, ainda, estudos sobre os trabalhos científicos produzidos no interior desses grupos, como também de propostas curriculares que se autodenominam de histórico-culturais. A hipótese é de que uma pesquisa dessa natureza contribuiria para apontar as diferentes leituras do referencial, os ecletismos e, acima de tudo, as intenções indicadoras de propósitos determinados por modismos teórico-pedagógicos ou um posicionamento adquirido por compreensões de mundo e sociedade defendidas. Nesse sentido, os desafios se apresentam, pois, como atividade de pesquisa, esta tem a característica de ser "atividade humana" (LEONTIEV, 1978). Sendo assim, tem um fim, um motivo, ações e operações para a compreensão do desenvolvimento do pensamento matemático no processo educativo.

É inegável que o referencial histórico-cultural tem se solidificado com o empenho de entender a realidade do processo educativo matemático em seus aspectos cognitivo e social, porém, com a conclamação de se evitar o ecletismo e o modismo teórico e pedagógico, mesmo que suscite obstáculos por parte da comunidade científica. O importante é a consciência de que os desafios são característicos de toda atividade humana e não poderia ser diferente quando se trata de uma perspectiva pedagógica e de pesquisa que prime por tal rigor, no que se refere ao processo educativo matemático.

Portanto, é animadora a perspectiva de uma educação matemática por via da teoria histórico-cultural pelo seu componente ético. Isso se evidencia ao explicitar uma visão de mundo, mesmo em sua base psicológica, quando se adota como matriz o materialismo histórico e dialético. Tal posicionamento é expresso por Vygotski:

Não chamaríamos de "darwinista" nossa biologia. Isto é algo que se inclui no próprio conceito de ciência, porque faz parte da ciência o reconhecimento das mais importantes concepções. Um marxista-historiador nunca diria "história marxista da Rússia". Consideraria que isto se depreende dos próprios fatos. "Marxista" é para ele sinônimo de "verdadeira, científica"; não reconhecemos outra história a não ser a marxista. E para nós a questão deve ser formulada assim: nossa ciência se tornará marxista na medida em que se tornar verdadeira, científica; e é precisamente à sua transformação em verdadeira, e não a coordená-la com a teoria de Marx, que nos dedicaremos (2004, p. 414-415, grifo do autor). 
Essa proposição teoriza a igualdade social como ponto de partida e de chegada da vida humana; não dicotomiza teoria-prática, concreto-abstrato, realidade-possibilidade. Também, prima pela formação humana em vez do utilitarismo do conhecimento matemático, isto é, com a prerrogativa eminentemente de utilização no campo profissional, futuro dos estudantes. Além disso, é coerente com os seus fundamentos, ao proceder à releitura constante de posicionamentos internos, sem perder de vista as intenções que a originaram e caracterizam seu desenvolvimento. O importante é que esse processo ocorre num coletivo de estudiosos desde sua gênese: Vygotski, Luria, Leontiev, Zaporózhets, Rubinstein, Galperin, Talyzina, Elkonin, Anániev, Ilienkóv, Davidov, Rubtsov, Zankov, Kruteskii, Kalmykova e outros. Entre eles, há que se ressaltar, houve estudos relacionados ao desenvolvimento de pensamento conceitual matemático, como também a tradução para o processo educativo escolar.

Contudo, expande-se a necessidade do aprofundamento dos estudos no referencial teórico em pauta, com o objetivo de contribuir para as condições de efetivação e expansão das iniciativas postas no contexto escolar e de pesquisa, no entanto, sem a preocupação de mera medida para melhoria de resultados numéricos de avaliação de desempenho de alunos e professores. Pelo contrário, a necessidade que promove a atividade de pesquisa, de ensino e de estudo é a constituição de um potencial para desvelar a realidade social, com adoção do conhecimento matemático como um processo de formação humana.

\section{Mathematics education: possibilities of a cultural-historical trend}

\section{Abstract}

This paper proposes a reflection on the possibility of emergence, in the Brazilian educational and scientific context, of a trend in mathematics education based on the cultural-historical theory. This study becomes relevant considering the indifference of the literature on the subject, in spite of the evidences in the fields of teaching and researching. Two arguments stand out: 1) the theoretical basis and its expression in researches related to mathematics teaching and learning as performed by Russian scholars such as Vygotski, Luria, Leontiev, Davydov, Galperin, Krutestskii, Kalmykova, and Talyzina. 2) research groups registered in the CNPq Lattes Platform, whose records explicit their study objects and their theoretical background based on the cultural-historical theory. Therefore, this paper presents some indicatives for future studies that could confirm or not the cultural- historical trend in mathematics education.

Keywords: Cultural-historical theory. Mathematics education. Trends. 


\section{Referências}

A PEDAGOGIA histórico-crítica e o ensino-aprendizagem da matemática. Grupo de pesquisa. [Diretório dos grupos de pesquisa no Brasil]. Disponível em: <http://dgp.cnpq.br/buscaoperacional/detalhegrupo.jsp?grupo=0330708MU3FOW5>. Acesso em: 27 mar. 2010.

BALDINO, R. R. Ensino de matemática ou educação matemática. Temas e Debates, São Paulo, Sociedade Brasileira de Educação Matemática, ano 4, n. 3, p. 51-60, 1991.

DAMAZIO, A. O desenvolvimento dos conceitos matemáticos no contexto do processo extrativo do carvão. 2000. Tese (Doutorado em Educação) - Universidade Federal de Santa Catarina, Florianópolis, 2000.

. A inter-relação pesquisa e tendência em educação matemática: manifestações de inserção social. In: QUARTIERO, E. M.; SOMMER, L. H. (Org.). Pesquisa, educação e inserção social: olhares da região sul. Canoas, RS: ULBRA, 2008. p. 99-119.

D’AMBROSIO, U. Etnomatemática: arte ou técnica de explicar ou conhecer. 2. ed. São Paulo: Atual, 1996.

DAVYDOV, V. Tipos de generalización en la enseñanza. Habana: Editorial Pueblo y Educación, 1982.

. La enseñanza escolar y el desarrollo psíquico: investigación teórica y experimental. Moscou: Progresso, 1988.

. La renovación de la educación y el desarrollo mental de los alumnos. Revista de Pedagogía, Santiago, año XLVIII, n. 403, p. 197-199, jun. 1998.

. Uma nova abordagem para a investigação da estrutura e do conteúdo da atividade. Trad. de José Carlos Libâneo. In: HEDEGARD, M.; JENSEN, U. J. (Org.). Activity theory and social practice: cultural-historical approaches. Aarhus (Dinamarca): Aarthus University Press, 1999. p. 39-50.

ELKONIN, D. B. Sobre el problema de la periodización del desarrollo psíquico en la infancia. In: DAVYDOV, V.; SHUARE, M. (Org.). La psicología evolutiva y pedagógica en la URSS (antologia). Moscou: Progresso, 1987. p. 125-142.

FERREIRA, L. S. Educação, paradigmas e tendências: por uma prática educativa alicerçada na reflexão. Revista Ibero-Americana de Educación, Madrid, v. 1, p. 12-21, 2003. Disponível em: < http://www.campus-oei.org/revi>. Acesso em: 12 mar. 2010.

FIORENTINI, D. Alguns modos de ver e conceber o ensino da Matemática no Brasil. Zetetiké, Campinas, ano 3, n. 4, p. 1-36, 1995.

; LORENZATO, S. Investigação em educação matemática: percursos teóricos e metodológicos. Campinas, SP: Autores Associados, 2006.

FLORIANI, J. V. Professor e pesquisador: exemplificação apoiada na matemática. 2. ed. Blumenau, SC: FURB, 2000.

GALPERIN, P. Y.; TALYZINA, N. F. La formación de conceptos geométricos elementales y su dependencia sobre la partipación dirigida de los alumnos. In: Psicología Soviética Contemporánea, Habana: Instituto del Libro, Série Ciencia e Tecnica, 1967. p. 273-302. 
. Sobre el método de formación por etapas de las acciones intelectuales. In: ILIASOV, I. I.; LIAUDIS, V. Y. Antologia de la psicologia pedagógica y de las edades. La Habana: Editorial Pueblo y Educación, 1986. p. 114-118.

GIARDINETTO, J. R. B. A matemática em diferentes contextos sociais: diferentes matemáticas ou manifestações da matemática? Reflexões sobre especificidade e a natureza do trabalho educativo escolar. In: REUNIÃO ANUAL DA ANPED, 25, 2002, Caxambu, MG. Anais... Caxambu, MG: Associação Nacional de Pós-Graduação e Pesquisa em Educação, 2002. Disponível em: <www.anped.org.br/.../25/.../joserobertogiardinettot19.rt.>. Acesso em: 12 mar. 2010.

GRUPO de estudos e pesquisa sobre atividade pedagógica. Grupo de pesquisa. [Diretório dos grupos de pesquisa no Brasil]. Disponível em: <http://dgp.cnpq.br/buscaoperacional/detalhegrupo.jsp?grupo=0067708GXKEOH3>. Acesso em: 27 mar. 2010.

GRUPO DE pesquisa e estudos histórico-culturais em educação matemática e em ciências. Grupo de pesquisa. [Diretório dos grupos de pesquisa no Brasil]. Disponível em: <http://dgp.cnpq.br/ buscaoperacional/detalhegrupo.jsp?grupo=0333708BIS4DLU>. Acesso em: 27 mar. 2010.

KALMYKOVA, Z. I. Pressupostos psicológicos para uma melhor aprendizagem da resolução de problemas aritméticos. In: LURIA, A. et al. (Org.). Pedagogia e psicologia II. Lisboa: Estampa, 1991. p. 9-26.

KRUTESTSKII, V. A. Algumas características do desenvolvimento nos estudantes com pouca capacidade para a matemática. In: LURIA, A. et al. (Org.). Pedagogia e psicologia II. Lisboa: Estampa, 1991. p. 35-57.

LEONTIEV, A. O desenvolvimento do psiquismo. Lisboa: Livros Horizonte, 1978.

LOPES, A. R. L. V.; BORBA, M. C. Tendências em educação matemática. Roteiro, Joaçaba, SC, n. 32, p. 49-61, jul./dez. 1994.

LURIA, A. Speech and intellect of rural, urban and homeless children. Selected Writings, Nova York: Sharpe, p. 37-71, 1978.

MIGUEL, A. O projeto de disciplinarização da prática social em educação matemática. In: REUNIÃO ANUAL DA ANPED, 26, 2003, Poços de Caldas, MG. Anais... Poços de Caldas, MG: Associação Nacional de Pós-Graduação e Pesquisa em Educação, 2003. p. 1-42. Disponível em: $<$ http://www.anped.org.br>. Acesso em: 3 maio 2010.

MOURA, M. O. de. A construção do signo numérico em situação de ensino. 1992. Tese (Doutorado em Educação) - Faculdade de Educação da Universidade de São Paulo, São Paulo, 1992.

PETRONZELLI, V. L. L. Educação matemática e a aquisição do conhecimento simbólico: alguns caminhos a serem trilhados. 2002. Dissertação (Mestrado em Educação) - Universidade Tuiuti do Paraná, Curitiba, 2002.

PRÁTICA pedagógica em matemática (Prapem). Grupo de pesquisa. Disponível em: <http:// dgp.cnpq.br/buscaoperacional/detalhegrupo.jsp?grupo=0079708LSCDP03>. Acesso em: 27 mar. 2010 .

PROCESSOS de ensino-aprendizagem em educação matemática. Grupo de pesquisa. [Diretório dos grupos de pesquisa no Brasil]. Disponível em: <http://dgp.cnpq.br/buscaoperacional/detalhegrupo.jsp?grupo=11737087HOYS19>. Acesso em: 27 mar. 2010.

SKOVSMOSE, O. Educação matemática crítica: a questão da democracia. Campinas, SP: Papirus, 2001. 
TALYZINA, N. F. La formación de las habilidades del pensamiento matemático. México: Universidad Autónoma de San Luis Potosí, 2001.

TRIVIÑOS, A. N. S. Introdução à pesquisa em ciências sociais: a pesquisa qualitativa em educação. São Paulo: Atlas, 1987.

VILELA, E. O. Eu pesquiso, tu pesquisas, eles... e quem ensina e quem aprende matemática? Um estudo sobre a produção acadêmica do GT Educação Matemática - Anped (2000 - 2007). Florianópolis: UFSC, 2008.

VYGOTSKI, L. S. Obras escogidas II: incluye pensamento y lenguaje, conferecias sobre psicología. Madrid: Visor Distribuciones, 1993.

. Obras escogidas III: incluye problemas del desarrollo de la psique. Madrid: Visor Distribuciones, 1995.

. Teoria e método em psicologia. Trad. de Claudia Berliner. 3. ed. São Paulo: Martins Fontes, 2004. 